\title{
Entitlement and Evidence ${ }^{1}$
}

\author{
Martin Smith
}

Entitlement is conceived as a kind of positive epistemic status, attaching to certain propositions, that involves no cognitive or intellectual accomplishment on the part of the beneficiary - a kind of positive epistemic status that is in place by default. In this paper I will argue that the notion of entitlement - or something very like it at any rate - falls out of an idea that may at first blush seem rather disparate; that the evidential support relation can be understood as a kind of variably strict conditional (in the sense of Lewis [1973]). Lewis provided a general recipe for deriving what he termed inner modalities from any variably strict conditional governed by a logic meeting certain constraints. On my proposal, entitlement need be nothing more exotic than the inner necessity associated with evidential support. Understanding entitlement in this way helps to answer some common concerns - in particular, the concern that entitlement could only be a pragmatic, and not genuinely epistemic, status.

Keywords: entitlement, evidence, variably strict conditional, inner modality

\section{INTRODUCTION}

Following Crispin Wright, call a proposition $\mathrm{P}$ a presupposition of a practice of inquiry iff to doubt that $\mathrm{P}$ (in advance) would rationally commit one to doubting the very significance or competence of the practice [see Wright 2004: pp191]. I'll leave this characterisation somewhat rough for the time being. A familiar sceptical line of

\footnotetext{
${ }^{1}$ This paper was presented at the Scots Philosophical Association Meeting in November 2009, at the University of Aberdeen in November 2009, at the Northern Institute of Philosophy Graduate Conference in July 2010, at the University of Copenhagen in October 2010 and at the European Epistemology Network Meeting in June 2012. The paper has benefitted enormously from comments and discussion on each of these occasions.
} 
thought proceeds in two stages: (i) By exposing the presuppositions that underlie our practices of inquiry and (ii) by exposing the apparently groundless or capricious manner in which these presuppositions are accepted.

Plausibly, the proposition that there are external objects serves as a presupposition of our practice of inquiring into the nature of our environment on the basis of perception and the proposition that there are other minds serves as a presupposition of our practice of attributing mental states on the basis of observed behaviour. Serious doubts about either of these propositions would quickly propagate throughout the associated practice, rendering it suspect in the eyes of the doubter. Clearly, though, these are not propositions that I have investigated in any sense - and I would be hard pressed to offer any non-question-begging considerations in their favour. In virtue of what, then, might I be justified in accepting these propositions? Surely if I've done nothing to investigate a proposition and have no resources to reassure a doubter, I should be somewhat doubtful of the proposition myself. How could I have justification for believing such a thing?

One of the anti-sceptical ideas that Wittgenstein explored in On Certainty might be regarded as broadly responsive to this line of thought. Wittgenstein conceded to the sceptic that we have no evidence in favour of the presuppositions underlying our practices of inquiry, but insisted that they are, nevertheless, certain for us [Wittgenstein 1969]. For Wittgenstein, these propositions are not certain because we have established them beyond doubt or assured ourselves of their truth - we have done no such thing. Rather, they are certain because they are a part of our basic 'world picture' or 'form of life'. As Wittgenstein writes: 
...I did not get my picture of the world by satisfying myself of its correctness; nor do I have it because I am satisfied of its correctness. No: it is the inherited background against which I distinguish between true and false.

[Wittgenstein 1969: §94, see also §86-88, 95, 358-359].

This approach can be further embellished by adding the thought that presuppositions are not genuinely fact-stating or truth-evaluable. Rather, so the thought goes, these propositions enshrine rules for the regulation of inquiry or the appraisal of evidence. To accept that there are external objects or other minds is not, on this view, to take any stance as to how the world is - it's not to commit oneself to the world being some particular way as opposed to some other way - it is just to acquiesce in a certain way of inquiring. There is some suggestion of this view in $O n$ Certainty. As Wittgenstein puts it:

And isn't it the same as if the pupil were to hold up his history lesson with doubts as to whether the Earth really...?

This doubt isn't one of the doubts in our game. (But not as if we chose the game!)

'The question doesn't arise at all.' Its answer would characterise a method. But there is no sharp boundary between methodological propositions and propositions within a method.

[Wittgenstein 1969: §316-318, see also §204-206, 214-215, 309, 319-321].

This idea is clearly designed to make more palatable the prospect of accepting presuppositions without supporting evidence, and it is a theme that has bulked large in some of the secondary literature on On Certainty [Wright 1985: section III, McGinn 1989: chaps. 7 and 8].

Abstracting away from the specifics of this view, the idea that seems to be doing the anti-sceptical work is surely very simple: It is possible for one to have prima facie justification for believing some propositions even though one has not conducted 
an inquiry into their truth and is in no position to offer non-question-begging considerations in their favour - it is possible for one to have prima facie justification for believing some propositions by default. One can't, of course, just intone this mantra and put scepticism to one side - it incurs an explanatory burden. How can one have justification for believing propositions that one has not investigated and can't properly defend? The claim that some propositions are non-fact stating can be understood as one way of attempting to discharge this burden - but there have been a number of different attempts to vindicate this distinctive species of justification or entitlement as it has come to be known [Wright 1985, 2000, 2002, 2003, 2004, Davies $2003,2004]^{2}$

Wright [2004] outlines a taxonomy of possible conceptions of entitlement. I won't explore Wright's proposals in detail here, but at least two of his conceptions namely strategic entitlement and entitlement of cognitive project - appear to be partly grounded in considerations borrowed from the domain of prudential rationality. Once we concede that the presuppositions underlying our practices of inquiry do embody

\footnotetext{
${ }^{2}$ Some authors prefer to reserve the term 'justification' for cases in which one has conducted an inquiry and is in a position to offer non-question-begging grounds, invoking some other term such as 'warrant' to subsume both entitlement and justification. I, like Pryor [2004], will use 'justification' as the catch-all term. Nothing explicitly hangs on this, but there may be a substantial issue lurking behind the terminological choice. While 'justification' is the more familiar piece of epistemological vocabulary, in the minds of most epistemologists justification is linked rather closely with knowledge in particular, justification is supposed to supply the needs of knowledge when combined with truth, belief and whatever external conditions are required to rule out Gettier cases. One who thought that entitlement did not link up with knowledge in this way may wish to resist classifying it as a species of justification for this very reason. I am inclined to think that entitlement does (and indeed must) supply the needs of knowledge in just the same way that any other kind of justification does - but this is an argument for another occasion.
}

Relatedly, some hold that an entitlement is a license to something less than full belief - a license to 'trust' a proposition or to 'take it for granted' [Wright 2004: section II]. This is another (related) reason to resist classifying entitlement as a species of epistemic justification - which is generally linked to belief. I'm inclined to think that entitlement must be understood as an entitlement to believe, if further problems are to be averted down the track - but I won't argue this here. Furthermore, one of the primary reasons for wanting to concede otherwise - i.e. concerns about entitlement's non-evidential status - turn out, in my view, to be chimerical. This is something that I shall discuss at some length below. 
substantial claims about the world, emphasising the practical benefits of accepting such propositions is, perhaps, a natural way of attempting to compensate for the lack of evidence in their favour. Explaining entitlement in this way, though, risks reducing it to a pragmatic, rather than genuinely epistemic, status - in which case one might worry whether it is suited to the anti-sceptical role that it is supposed to play [see Pritchard 2005, Jenkins 2007] $]^{3}$.

In this paper, I shall approach the topic of entitlement from a somewhat unfamiliar direction - via a formal theory of evidential support. As I shall show, a notion of entitlement emerges, as a kind of by-product, from one rather natural way of thinking about this. That is, thinking about just how the evidential support relation works formally gestures towards a novel conception of entitlement. I shall outline this conception of entitlement in the next section.

Although motivated on independent grounds, this conception of entitlement will be capable of performing the anti-sceptical work demanded of it. That is, it will turn out that entitlement, so conceived, will attach to the presuppositions of legitimate practices of inquiry. I shall return to the topic of scepticism in section III. Unlike others, I won't be invoking any semantic or practical considerations in order to help us stomach the idea that presuppositions can be justifiably believed without evidence. On my account, we need not stomach this idea at all - unlike all extant conceptions of entitlement, the present conception does not make entitlement into something non-

\footnotetext{
${ }^{3}$ Hazlett [2006] emphasises the epistemic benefits of accepting presuppositions - roughly, that accepting presuppositions will put us in a position to acquire a great deal of knowledge that would otherwise be closed to us - and suggests that this consideration might motivate the claim that entitlement is an epistemic status. In my view, the fact that a belief furthers our interests can never make for epistemic justification, irrespective of whether those interests are broadly epistemic ones. I won't pursue this here - but see Jenkins [2007].
} 
evidential. As such, it should leave us in no doubt as to its genuinely epistemic status. I shall discuss this, and other distinctive features of the present conception of entitlement, in section IV.

\section{EVIDENTIAL SUPPORT}

I propose to treat evidential support as a kind of modal relationship. More precisely, I propose to treat evidential support as a species of variably strict conditional in the sense of Lewis [1973]. On this sort of view, what it takes for a piece of evidence E to provide support for a proposition $\mathrm{P}$ is for $\mathrm{E}$ and $\mathrm{P}$ to be distributed in the right sort of way throughout certain important possible worlds.

Lewis was primarily concerned to provide a semantic analysis for counterfactual conditionals and, to this end, he supplemented the standard apparatus of possible world semantics with the idea that possible worlds stand in relations of comparative similarity or resemblance to one another. According to Lewis, a conditional such as 'If it had not rained today, then we would have gone to the cricket' means something like: In any possible world in which the weather is fine and which resembles the actual world as much as the weather being fine permits it to, we go to the cricket. Alternately, it means that the most similar worlds in which it is not raining and we go to the cricket are more similar than the most similar worlds in which it is not raining and we do not go to the cricket.

Let $\mathrm{w}$ be the index world at which a counterfactual conditional is being evaluated. If we visualise possible worlds arranged in space, with proximity serving 
as a metaphor for similarity, then we can imagine a series of concentric spheres radiating out from $\mathrm{w}$ - each representing a class of worlds that resemble w equally. This is the mathematician's sense of sphere - a locus of points (in three-dimensional space) equidistant from a single point. Now think of a sphere as being solid rather than hollow - containing not just the worlds that compose its surface, but also those that fall inside it. This is how Lewis intends that the term be used. For Lewis the system of spheres associated with an index world can be totally ordered by inclusion or 'size' - a constraint he terms nesting.

According to Lewis, the smallest nonempty sphere in a system will be a set containing just the index world. Presumably no world resembles the index world more closely than, or as closely as, it resembles itself. The largest sphere in a system will be the set containing all the worlds that are metaphysically possible from the perspective of the index world. Say that a sphere around a world $\mathrm{w}$ permits a proposition just in case it contains worlds at which the proposition is true. In order to determine whether a counterfactual conditional holds true at w, we travel out from w, sphere by sphere, until we encounter worlds in which the antecedent holds. If all of the antecedent-worlds subsumed in this sweep are also consequent-worlds, then the conditional will be true at $\mathrm{w}-$ otherwise it will be false.

Lewis introduces two counterfactual conditional operators $\square \rightarrow$ and $\diamond \rightarrow$ to be read respectively as 'If _ the case, then ... might be the case' [see Lewis 1973: 1-2]. The truth conditions for the two operators can be given as follows: 
$\mathrm{P} \square \rightarrow \mathrm{Q}$ is true at a world w iff there exists a P-permitting sphere of similarity around $\mathrm{w}$ in which all the $\mathrm{P}$-worlds are also Q-worlds.

$\mathrm{P} \diamond \rightarrow \mathrm{Q}$ is true at a world $\mathrm{w}$ iff in all $\mathrm{P}$-permitting spheres of similarity around $\mathrm{w}$, there exists a $(\mathrm{P} \wedge \mathrm{Q})$-world.

Lewis allows for one exception: $\mathrm{P} \square \rightarrow \mathrm{Q}$ should be deemed vacuously true at $\mathrm{w}$ and $\mathrm{P} \diamond \rightarrow \mathrm{Q}$ vacuously false if there is no P-permitting sphere of similarity around w. These two operators are interdefinable as follows: $(\mathrm{P} \square \rightarrow \mathrm{Q}) \equiv \sim(\mathrm{P} \diamond \rightarrow \sim \mathrm{Q})$.

On Lewis's account, counterfactual conditionals work, semantically, rather like strict conditionals do - by universally quantifying over a class of possible worlds. However, while the quantificational range of a strict conditional, at a given world, is constant, the quantificational range of a counterfactual conditional varies as a function of the antecedent - it quantifies over the smallest sphere of similarity to accommodate the antecedent's truth. In Lewis's view, a range of conditionals, besides ordinary counterfactuals, might be regarded as variably strict. In the abstract, all that the truth conditions for a variably strict conditional require is some way of ranking possible worlds, so as to determine the various possible quantificational ranges. And, presumably, possible worlds could be ranked according to any number of parameters besides comparative similarity.

Consider the deontic conditional 'If Jesse robbed the bank, then he ought to return the loot and confess'. When evaluating a conditional like this, it seems that we are still interested in the properties of certain possible worlds in which Jesse robs the bank. But, rather than selecting these worlds on the basis of the extent to which they 
resemble the actual world, we would be better served by examining the degree to which they exemplify some moral ideal. According to Lewis, the conditional means something like: In any possible world in which Jesse robs the bank and which is as good as Jesse's robbing the bank permits it to be, Jesse confesses and returns the loot. Alternately, it means that the best worlds in which Jesse robs the bank and then confesses and returns the loot are better than the best worlds in which Jesse robs the bank without confessing and returning the loot [see Lewis 1973: section 5.1]. Similar suggestions have been made by Hansson [1969] and Van Fraassen [1973].

If sphere systems are taken to represent comparative similarity to an index world $w$, then it is only natural that $\{w\}$ should always be the smallest nonempty sphere. Lewis terms this constraint centering. Other ways of ranking worlds, however, need not share this feature. In a weakly centered system of spheres, while the index world remains an element of the smallest nonempty sphere around itself, it is no longer the sole element - further worlds are permitted to infiltrate. Finally, in a decentered system of spheres, the index world need not even be a member of the smallest nonempty sphere. If a sphere system is intended to represent the comparative goodness of possible worlds from the perspective of the index world, then there is no particular reason to expect that the system will be centered or even weakly centered. These conditions will only be met on the proviso that the index world estimates itself to be perfect and this will not, in general, be the case.

Evaluating a deontic conditional involves a kind of idealisation. When I judge that, if Jesse robbed the bank, he ought to return the loot and confess, I am, for instance, idealising away from the possibility that Jesse's confession would trigger 
revenge attacks and cause untold suffering. The best worlds at which Jesse robs the bank just won't be like this - they will be idealised in appropriate respects. Evaluating whether one thing counts as evidence in favour of another can also, I think, involve a kind of idealisation. When, for instance, I judge that the wall's red appearance is evidence that the wall is red I am, in effect, idealising away from the possibility that the wall is illuminated by tricky red light.

The idealisation involved here is not of a romantic sort - but, rather, of a simplifying or normalising sort - a practice which is, I think, just as familiar. Rather than giving us a comparative goodness ordering of worlds, idealisation of this kind will generate what we might think of as a comparative normalcy ordering of worlds. The most normal worlds in which the wall appears to be red won't be worlds in which there is tricky red light shining on the wall - they will be idealised in appropriate respects.

Let's use this ordering to define two variably strict conditional operators:

$\mathrm{P} \boldsymbol{\square} \rightarrow \mathrm{Q}$ is true at a world w iff there exists a P-permitting sphere of normalcy associated with $\mathrm{w}$ in which all the P-worlds are also Q-worlds.

$\mathrm{P} \diamond \rightarrow \mathrm{Q}$ is true at a world $\mathrm{w}$ iff in all P-permitting spheres of normalcy associated with $\mathrm{w}$, there exists a $(\mathrm{P} \wedge \mathrm{Q})$-world.

I shall allow for the same kind of exception as Lewis: $\mathrm{P} \boldsymbol{\mathbf { m }} \rightarrow \mathrm{Q}$ should be deemed vacuously true at $\mathrm{w}$ and $\mathrm{P} \diamond \rightarrow \mathrm{Q}$ vacuously false if there is no P-permitting sphere of normalcy around w. 
I suggest that $\rightarrow$ can be read 'That $\ldots$ is evidence that $\_$' or 'The proposition that ... provides evidential support for the proposition that _ '. Call this an evidential conditional ${ }^{4}$. 'That the wall appears to be red is evidence that the wall is red' will be true just in case the following holds: In any possible world in which the wall appears to be red and which is as normal as the wall's appearing to be red permits it to be, the wall is red. Alternately, the claim is true iff the most normal worlds in which the wall is red and appears to be red are more normal than the most normal worlds in which the wall is some other colour and appears to be red $^{5}$. Expressions such as 'That ... is evidence that it might be the case that _ ' can, perhaps, be formalised using $\diamond \rightarrow$. I'm not particularly committed to this - though I do make one use of it in the next section.

\footnotetext{
${ }^{4}$ The idea that evidential relations might be modelled using a comparative normalcy ordering of possible worlds is one that I've explored in previous work [Smith 2009, 2010]. Another area in which this sort of idea features is the semantics for defeasible or nonmonotonic logics [see for instance Kraus et. al. 1990, Makinson 1989, Boutilier 1995, Huber 2009: section 5.2]. The semantic apparatus employed, however, is typically more austere than the one developed here - limited, in a way, to the resources of standard possible world semantics. One typical kind of model takes the form $\langle\mathrm{W},<\rangle$ where $\mathrm{W}$ is a set of possible worlds and $<$ is a transitive, irreflexive relation on $\mathrm{W}$ to be read ' $\ldots$ is more normal than _.'. The simplest associated rule for evaluating defeasible support has it that $\mathrm{P}$ defeasibly supports Q just in case all of the <-minimal P-worlds are Q-words.
}

As it stands, this kind of semantic apparatus makes no provision for the comparative normalcy ranking of worlds to itself be world relative. This partially reflects the fact that defeasible support is typically regarded as a meta-level consequence relation, conceived by analogy with logical consequence, rather than a connective of the object language - effectively blocking the formation of the embedded constructions for which world relativity/absoluteness can make a difference. The predictions that absoluteness makes with respect to embedded constructions are not, I think, desirable. For discussion of these issues see Makinson [1993: section 3].

${ }^{5}$ Such analyses, as they stand, are not meant to imply that facts about comparative world normalcy enjoy any kind of priority over facts about evidential support - they merely state a necessary connection between the two. Indeed, these analyses are compatible with the view that facts about comparative world normalcy are determined by facts about what evidentially supports what. From this perspective, the reason that the most normal worlds in which the wall appears to me to be red are worlds in which it is red is precisely that the former proposition provides evidential support for the latter. I take no stand here on whether facts about comparative world normalcy or facts about evidential support should be regarded as primary. This issue is of no immediate importance for present purposes - though it may assume some significance when it comes to determining just what sort of response to the sceptic might be extracted from the present framework. I'll have more to say about this in footnote 19 . 
It's worth noting right away that examples involving necessary truths or falsehoods present prima facie problems for this account. It will turn out, on this account, that anything will be evidence for a necessary truth and a necessary falsehood will be evidence for anything. More generally the present account predicts that necessary truths can be freely substituted and necessary falsehoods can be freely substituted within evidential conditionals (provided they don't also fall under the scope of another operator). Lewisian accounts of counterfactuals and deontic conditionals will, of course, make the same prediction [see Lewis 1973: section 1.6]. Lewis appears to think that the potentially counterintuitive consequences that ensue should be tolerated as by-products of an otherwise successful systematisation of our intuitions. I am tempted to take a similar attitude - but there may be special reasons for thinking that evidential conditionals create hyperintensional contexts ${ }^{6}$. For present purposes I shall bracket this issue. The account I have outlined does, I suggest, offer the right truth conditions when both antecedent and consequent of an evidential conditional are contingent. I limit myself to such cases here.

An important part of the case for treating evidential support in the way I've suggested concerns the logical predictions that the treatment makes - that is, predictions about the logical principles governing the evidential support relation. I'm inclined to think that these logical predictions are, for the most part, apposite - but I won't argue this in any detail here, limiting myself to a few notable examples:

\footnotetext{
${ }^{6}$ The prediction that anything constitutes evidence for a necessary truth might be thought particularly troubling in the case of a posteriori necessities - but even here matters are not entirely straightforward. Consider the putatively necessary a posteriori truth that Cicero is Tully. Direct reference theorists, in so far as they continue to work within the framework of propositions, and accept a plausible compositionality thesis, must take 'Cicero is Tully' to expresses the very same proposition as 'Cicero is Cicero' [for some discussion see Soames 2002: chaps. 1 and 8]. Thus, this proposition will be knowable a priori, just not under certain 'modes of presentation'. What I am proposing to analyse here is an evidential support relation between propositions. The account, as it stands, is silent on what it takes for something to count as evidence for a proposition under a particular mode of presentation, if there be such a thing to be analysed.
} 
The following inference - antecedent strengthening - will turn out to be invalid on the present approach:

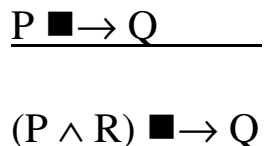

This reflects the fact that evidential support is defeasible - just because a certain body of evidence supports a proposition, this is not to say that an enriched or supplemented body of evidence will support the proposition. If decentered sphere systems are permitted, then modus ponens will also be invalid:

$\mathrm{P}$

$\underline{\mathrm{P} \boldsymbol{\mathbf { }} \rightarrow \mathrm{Q}}$

Q

This provides another, slightly different, way of thinking about defeasibility - it reflects the fact that one may possess evidence supporting a false proposition.

Finally, provided spheres are nested, variably strict conditionals will support the following inference - a restricted form of hypothetical syllogism:

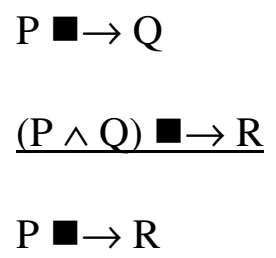

It's plausible that evidential support is cumulative in the sense that propositions supported by an initial body of evidence can be safely added to that stock in the service of supporting further conclusions. The validity of the above inference guarantees that, by doing this, I won't be lead to any conclusions that are not supported by the initial evidence. This, in effect, vindicates reasoning in chains. 
There is, naturally, a great deal more to be said about the logical predictions of the present approach - but to explore this further would take me too far from my stated aim.

Although I speak here of 'the' evidential support relation, I don't mean to suppose that only one relation might legitimately go by this name. In fact, I'm inclined to think that there are several support-type relations that evidence can bear to hypotheses - and they may well exhibit different kinds of logical properties. The relation modelled here is intended to have a particularly intimate connection to epistemic justification - at least when combined with some account of what it takes for one to possess a piece of evidence. In a nutshell, the idea is this: one will have prima facie justification for believing a proposition $\mathrm{P}$ just in case one possesses evidence that supports $\mathrm{P}$ in this sense, and one will have ultima facie or all things considered justification for believing $\mathrm{P}$ just in case $\mathrm{P}$ is supported, in this sense, by one's total corpus of evidence ${ }^{7,8}$.

\footnotetext{
${ }^{7}$ My account of evidential support is compatible with a range of different views about what it takes for a proposition to count as part of one's body of evidence. The sceptical arguments outlined in section I appear to take for granted a picture on which the scope of one's evidence is relatively circumscribed limited to propositions about one's own experiences or some such. While I have effectively conceded this for present purposes I don't mean to take an official stand on the issue here. There are, of course, generous accounts on which one's evidence can include propositions about external objects or others' mental states [McDowell 1982, Williamson 2000: chap. 9]. Such accounts may provide an alternative way of engaging sceptical arguments without the need for entitlement. I'm inclined to doubt, though, that generous accounts of evidence can completely obviate the need for a notion like entitlement. No matter how generous we are regarding the scope of one's evidence, we must ultimately recognise a point at which evidence ends and hypothesis begins. But wherever we cross this line, a sceptical argument of the sort outlined in section I will be able to secure a foothold. While generous accounts of evidence may draw this line in a different place, they cannot eliminate it altogether. For some related discussion see Wright [2004: 172-174].

${ }^{8}$ These connections link evidential support and propositional justification (of the prima facie and ultima facie varieties). Presumably, in order for one to justifiably believe a proposition $\mathrm{P}$ it will be necessary both that $\mathrm{P}$ be evidentially supported by one's total body of evidence and that my belief that $\mathrm{P}$ be based upon some piece of evidence within this corpus that evidentially supports it. We may wish to impose further necessary conditions as well - concerns over the relative ease with which these conditions could be satisfied for necessary truths may provide us with some impetus for doing so. I won't explore this further here.
} 
Given any variably strict conditional, and associated world ranking, we can define a pair of unary modal operators - namely, operators that quantify, at a given world, over the largest sphere assigned to it $^{9}$. Lewis refers to these as the outer modalities. Lewis suggests that the outer modalities associated with the counterfactual conditional should simply be interpreted as metaphysical necessity and possibility. We should, perhaps, say the same about the outer modalities connected with the deontic and evidential conditionals ${ }^{10}$. For certain kinds of variably strict conditional, we can also define a pair of substantial inner modalities - operators that quantify, at a given world, over the smallest nonempty sphere assigned to it ${ }^{11}$. With centering in place, the inner modalities will simply collapse into truth - but if weakly centered or decentered systems are permitted, then they will enjoy some modal strength $^{12}$.

On Lewis's account, then, counterfactual conditionals will not support substantial inner modalities. Deontic and evidential conditionals, however, will. Let

\footnotetext{
${ }^{9}$ Or over the union of all spheres in case there is no largest sphere.

${ }^{10}$ Depending upon how one thinks about goodness, one may acknowledge the possibility of worlds that impose no standards of goodness whatsoever and, thus, are assigned only an empty goodness sphere. If one held a divine command theory of morality, for instance, one might take this attitude towards worlds that lack an appropriate deity. At these worlds, all propositions will satisfy the deontic outer necessity and none will satisfy the deontic outer possibility. Admitting such worlds would effectively block any attempt to interpret the deontic outer modalities as the familiar metaphysical ones - leaving their interpretation somewhat unclear. Whether the evidential outer modalities can be interpreted as the metaphysical modalities will depend, in a similar way, on whether we permit the possibility of worlds that impose no standards of normalcy whatsoever. I think this is an intriguing issue - but one that is tangential to present concerns.

${ }^{11}$ If there is no smallest nonempty sphere assigned to a world then the inner modalities have to be understood in a slightly different way. See footnote 13 .

${ }^{12}$ In syntactic terms, the inner modalities associated with a variably strict conditional $\square \rightarrow$ will be governed by a collapsed modal logic if we have what is sometimes termed conjunctive sufficiency: $(\mathrm{P} \wedge \mathrm{Q}) \supset(\mathrm{P} \square \rightarrow \mathrm{Q})$. With centering enforced, this will hold. If weakly centered systems are permitted then conjunctive sufficiency will fail, but modus ponens will be retained: $(\mathrm{P} \wedge(\mathrm{P} \square \rightarrow \mathrm{Q})) \supset$ Q. In this case the inner modalities will be governed by a modal logic at least as strong as KT. If decentered systems are permitted then even modus ponens will fail and the inner modalities can be governed by even weaker modal logics. The relationship between conditional logics and the inner modal logics that they generate is discussed further in Lewis [1973: section 6.3].
} 

be the inner necessity and possibility associated with the evidential conditional, furnished with the following truth conditions:

D is true at a world w iff all of the worlds in the smallest nonempty sphere of normalcy around w are P-worlds.

P is true at world $\mathrm{w}$ iff the smallest nonempty sphere of normalcy around $\mathrm{w}$ is P-permitting ${ }^{13}$.

Lewis suggests that the inner necessity associated with the deontic conditional will be a kind of unary obligation operator to be read 'It ought to be the case that...' or 'It is obligatory that...' [Lewis 1973: section 5.1]. The question of how the inner necessity associated with the evidential conditional should be understood is, in a way, the focus of this paper.

Recall the proposed connection between evidential support and epistemic justification: If one possesses some evidence $\mathrm{E}$ such that $\mathrm{E} \boldsymbol{\mathbf { m }} \rightarrow \mathrm{P}$, then one has prima facie justification for believing P. Given the semantics outlined so far, the following inference is clearly valid:

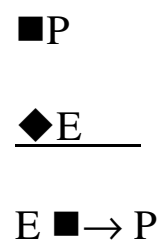

That is, $\mathbf{P}$ entails $\mathrm{E} \rightarrow \mathrm{P}$ for any $\mathrm{E}$ such that $\diamond \mathrm{E}$, including tautologies. Assuming that (some) tautologies are part of one's evidence by default then, if $\mathbf{\square P}$, one will have prima facie justification for believing $\mathrm{P}$ by default. If $\mathbf{D}$, one will have prima facie justification for believing $\mathrm{P}$, irrespective of whether one has investigated $\mathrm{P}$ or is in any

\footnotetext{
${ }^{13}$ Abstracting away from the assumption that each world must be assigned a unique smallest nonempty sphere of normalcy, the truth conditions for $\mathbf{a}$ and could be given as follows: $\mathbf{D P}$ is true at a world wiff there exists a nonempty sphere of normalcy associated with $\mathrm{w}$ in which all worlds are P-worlds. $\diamond \mathrm{P}$ is true at world $\mathrm{w}$ iff all nonempty spheres of normalcy associated with $\mathrm{w}$ are P-permitting. I ignore this kind of complication in the main text.
} 
position to offer non-question-begging grounds in its favour. Entitlement was defined, in the last section, as a kind of justification that one can possess by default - a kind of justification for believing a proposition that one can possess without having investigated the proposition and without being able to offer non-question begging grounds in its favour. As such, this is an initial, tentative case for identifying and entitlement - or, more cautiously, for treating $\mathbf{a s}$ being sufficient for entitlement, as defined.

As I mentioned in the last section, another idea that is thought to be part and parcel of the definition of entitlement is the idea that entitlement is non-evidential in nature - a kind of justification that owes nothing to evidence [see Wright 1985: section III, 2004: 174-175). But this will only follow from the definition on the assumption that evidence can never be possessed by default - that it must always be earned through investigation or inquiry. And this assumption should, I think, be resisted. In any case, $\mathbf{D P}$ clearly does not guarantee that one has a non-evidential justification for believing that $\mathrm{P}$. In a sense, the very opposite is true - if $\mathbf{D}$ then $\mathrm{P}$ will be supported by a torrent of evidence. I will return to this in section IV.

As discussed in the last section, the most familiar motivation for positing a notion of entitlement is to deflect certain sceptical arguments. As Tucker [2009] observes, while other ways of motivating the existence of entitlement are conceivable, none have, as yet, been devised [Tucker 2009: section VI]. If the reasoning of this section is on the right track, though, then we may have the beginnings of an independent motivation for accepting the existence of entitlement - one that bears no direct relation to sceptical arguments. But, while the present conception of 
entitlement is not directly motivated by sceptical concerns, it can, nevertheless, be used to address sceptical concerns - or so I hope to argue in the next section.

Before moving on, it is worth noting that $\mathbf{D}$, while it may guarantee that I have prima facie justification for believing $\mathrm{P}$, need not guarantee that I have ultima facie justification for doing so. If my evidence consists, in part, of propositions that do not hold in any maximally normal worlds - that is, propositions E such that $\sim \mathrm{E}-$ then $\mathrm{P}$ need not be supported by the totality of my evidence. Entitlement, on the present proposal, will be defeasible - prima facie and ultima facie entitlement can come apart ${ }^{14}$. Further, even if my entitlement to believe that $\mathrm{P}$ is ultima facie - even if $\mathrm{P}$ and $\mathrm{P}$ is supported by the totality of my evidence - this is not to say that a belief that $\mathrm{P}$ will automatically count as justified, irrespective of how I form it. As is well known, the relationship between propositional justification and doxastic justification is not straightforward [see Korcz 1997 and footnote 8]. Without exploring this in detail, all we can really say is that, if I have an ultima facie entitlement to $\mathrm{P}$, then a certain impediment to my justifiably believing that $\mathrm{P}$ will not be in place. Questions about how entitlement relates to justified belief are important - but I will focus primarily on propositional justification here ${ }^{15}$.

\footnotetext{
${ }^{14}$ Wright makes it a condition of the possession of entitlement of cognitive project that one not possess sufficient reasons for thinking that the proposition in question is untrue [Wright 2004: 191]. In my view, this should be a condition only upon the possession of ultima facie entitlement.

${ }^{15}$ If we accept the present account of evidential support wholeheartedly and follow where it leads even with respect to noncontingent propositions then, as discussed above, we would have to accept that anything will count as evidence in favour of a necessary truth, in which case we must be automatically entitled to any necessary truth. One reason I'm relatively unperturbed about this result is that the epistemic slack it appears to create could in principle be taken up by the relationship between propositional justification and justified belief. As I suggest in the text, one way to think about propositional justification is in terms of the absence of a certain impediment to justified belief - if I have propositional justification for P then I won't be prevented from justifiably believing $\mathrm{P}$ for lack of empirical evidence. If $\mathrm{P}$ is a complicated mathematical truth then I may not be in a position to justifiably believe it - but it won't be for lack of empirical evidence that this is so.
} 


\section{SCEPTICISM, ENTITLEMENT AND}

I will begin this section by briefly considering the notion of epistemic defeat. Suppose E provides evidence for P. In a well-known discussion of defeat John Pollock suggests that a proposition D defeats this evidential connection just in case D provides evidence for thinking that $\mathrm{P}$ might be false even though $\mathrm{E}$ is true [see Pollock 1974: pp42-43]. Suppose I see what appears to be a red wall and come to believe that the wall is red. Suppose I then learn that the wall is illuminated by tricky red light. This clearly serves to defeat my initial evidence and Pollock's suggestion seems to provide a very natural explanation as to why: That there is tricky red light shining on the wall provides evidence for thinking that the wall might not be red, even though it appears to be. After all, a white wall illuminated by tricky red light will appear to be red.

The claim that $\mathrm{D}$ provides evidence that $\mathrm{P}$ might be false even though $\mathrm{E}$ is true is quite naturally formalised as $\mathrm{D} \diamond \rightarrow(\mathrm{E} \wedge \sim \mathrm{P})-$ which is true just in case some of the most normal $\mathrm{D}$ worlds are worlds in which $\mathrm{E}$ is true and $\mathrm{P}$ is false. This is perfectly consistent with $\mathrm{E} \rightarrow \mathrm{P}$ - with all of the most normal $\mathrm{E}$ worlds being $\mathrm{P}$ worlds. One kind of situation in which both hold is depicted here: 


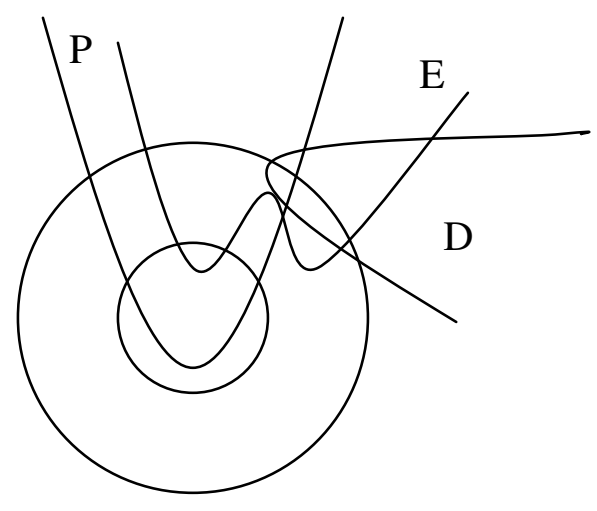

Fig. 1.

In this diagram, the inner circle represents those worlds that are maximally normal from the perspective of the index world and the outer ring represents those that rank next in terms of comparative normalcy.

In all of the most normal worlds in which the wall appears to be red, it will be red. But in some of the most normal worlds in which there is tricky red light illuminating the wall, the wall will appear to be red even though it is, in fact, white. Accommodating this defeater forces us, in effect, to travel further from idealised normalcy - to consider an expanded class of worlds in which the modal connection between appearance and reality is destabilised ${ }^{16}$.

It is plausible that there is an intimate connection between the notion of epistemic defeat and the notion of a presupposition of a practice of inquiry as roughly characterised at the outset. Consider a very simple, circumscribed practice of inquiry

\footnotetext{
${ }^{16}$ Pollock famously distinguished between two different ways in which a proposition D might qualify as a defeater for the evidential connection between $\mathrm{E}$ and $\mathrm{P}$ - either $\mathrm{D}$ provides evidence against $\mathrm{P}$ that serves to counterbalance or outweigh the evidence that $\mathrm{E}$ provides in its favour, or $\mathrm{D}$ serves to undermine the connection between $\mathrm{E}$ and $\mathrm{P}$. The red wall defeater considered here is an example of the second kind. It may be possible to capture this distinction within the framework I've developed, but I won't pursue this here.
} 
- a practice of treating one proposition $\mathrm{E}$ as evidence for another proposition $\mathrm{P}$. Suppose this practice is legitimate in that E really does constitute evidence in favour of $\mathrm{P}$. If $\mathrm{S}$ counts as a presupposition of this practice, such that serious doubts about $\mathrm{S}$ would prevent one from rationally concluding that $\mathrm{P}$ on the basis of $\mathrm{E}$, then, presumably, it must be the case that $\sim \mathrm{S}$ serves to defeat the evidential connection between $\mathrm{E}$ and $\mathrm{P}$. If $\sim \mathrm{S}$ did not defeat the evidential connection between $\mathrm{E}$ and $\mathrm{P}$ then it is unclear why doubts about $\mathrm{S}$ should have this effect. Combining this principle with the proposed account of defeat, we can derive a necessary condition upon the presupposition relation: If $\mathrm{S}$ is a presupposition of the true evidential conditional $\mathrm{E}$ $\mathbf{\square} \rightarrow \mathrm{P}$ then $\sim \mathrm{S} \diamond \rightarrow(\mathrm{E} \wedge \sim \mathrm{P})^{17}$

Broader practices of inquiry, I suggest, can be modelled by sets of evidential conditionals, corresponding to the various evidential transitions that are licensed. In the most general sense, of course, there is more to a practice of inquiry than simply treating some things as evidence for others - but this aspect is what seems essential for present purposes. What it is for a practice to be legitimate, on this picture, is simply for the evidential conditionals that constitute it to be true. Let's say that $\mathrm{S}$ is a presupposition of a set of true evidential conditionals $\left\{\mathrm{E}_{1} \rightarrow \mathrm{P}_{1}, \mathrm{E}_{2} \rightarrow \mathrm{P}_{2}, \ldots\right.$,

\footnotetext{
${ }^{17} \mathrm{We}$ might also regard this as a sufficient condition for $\mathrm{S}$ to count as a presupposition of the true evidential conditional E $\rightarrow$ P. I have some reservations about this, however. Think again of the red wall case. The proposition that there is tricky red light shining on the wall defeats the evidential connection between the wall appearing to be red and its being red. But would doubts about this proposition necessarily prevent me from rationally availing myself of this evidential connection? It seems that they would not. What if my doubts about the colour of the ambient lighting were combined with a firm conviction that a strong white spotlight was illuminating a point in the centre of the wall? Surely, then, I would be in a position to conclude that the wall is red on the basis of its red appearance.

All that this example exploits is the possibility of higher-order defeat - the fact that defeaters can themselves be defeated. There are a number of lessons that one might take from this. One might think that it points towards a useful refinement of the notion of a presupposition - that doubts about a presupposition should only be required to undermine a practice ceteris paribus or some such. I won't discuss this further here. For present purposes it is enough that the stated condition be necessary for the presupposition relation.
} 
$\left.E_{n} \rightarrow P_{n}\right\}$ iff it is a presupposition of each individual member - only if, for any i, $1 \leq$ $\mathrm{i} \leq \mathrm{n}, \sim \mathrm{S} \diamond \rightarrow\left(\mathrm{E}_{\mathrm{i}} \wedge \sim \mathrm{P}_{\mathrm{i}}\right)$.

My practice of attributing mental states on the basis of behaviour involves, for instance, treating Julie's tears and downcast expression as evidence for her being upset. My doing so is legitimate. In the most normal worlds in which Julie is crying and looking downcast, she is upset. But in some of the most normal worlds in which there are no other minds and others are mere automata, Julie is crying without feeling any sadness - or, indeed, feeling anything at all. Indeed it seems clear that all of the behaviour-mental state conditionals that constitute this vast practice would be defeated by the proposition that there are no other minds.

If investigating a proposition involves starting out with an open mind, then an investigation into a presupposition of a given practice of inquiry will not even get off the ground unless one is able to deploy an additional practice of inquiry for which it is not a presupposition. To be genuinely open minded about a proposition is to suspend the use of any evidential transitions that presuppose it. Clearly, then, one will not be in a position to offer a rationally persuasive defence of a presupposition from within the confines of the very practice it underpins. A doubter will refuse to reason in the way that the practice sanctions.

We now have before us a necessary condition for presupposition-hood - if $\mathrm{S}$ is a presupposition of the true evidential conditional $\mathrm{E} \rightarrow \mathrm{P}$ then $\sim \mathrm{S} \diamond \rightarrow(\mathrm{E} \wedge \sim \mathrm{P})-$ and a sufficient condition for entitlement - if $\mathbf{D P}$ then one is entitled to P. Given these conditions, will it be the case that we are entitled to the presuppositions of true 
evidential conditionals? To see that this is indeed the case, we need only note that the following inference is valid:

$\mathrm{E}$

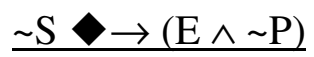

$\mathbf{n}$

That is, if all of the most normal worlds in which $\mathrm{E}$ is true are worlds in which $\mathrm{P}$ is true, and some of the most normal worlds in which $\mathrm{S}$ is false are worlds in which $\mathrm{E}$ is true and $\mathrm{P}$ is false, then all maximally normal worlds must be worlds in which $\mathrm{S}$ is true. A little more carefully, if there is an E-permitting sphere of normalcy associated with $\mathrm{w}$ in which all E worlds are P worlds and in all $\sim$ S-permitting spheres around w, some E worlds are $\sim \mathrm{P}$-worlds, then there must be some nonempty sphere associated with $\mathrm{w}$ which does not permit $\sim \mathrm{S}-$ that is, a sphere throughout which $\mathrm{S}$ holds.

If a presupposition of a true evidential conditional must be an evidential inner necessity and, as I argued in the previous section, we are entitled to accept evidential inner necessities, then we have the anti-sceptical result that we require: Whenever a practice of inquiry is legitimate, one will be entitled to its presuppositions. Indeed, in order for entitlement to play its anti-sceptical role - in order for it to attach to the presuppositions of legitimate practices - it never need outstrip the scope of evidential inner necessity. As far as the anti-sceptical role of entitlement is concerned, one might as well identify it with evidential inner necessity ${ }^{18}$.

\footnotetext{
${ }^{18}$ One might worry that a range of propositions, other than the presuppositions of legitimate practices of inquiry, may turn out to be evidential inner necessities. One might worry that entitlement, on my proposal, will end up attaching to more propositions than is required in order for it to play its antisceptical role, and that these 'superfluous' entitlements might lead to an overly permissive epistemology. Presumably the maximally normal worlds will all be worlds in which, say, the Earth revolves around the Sun - or so we might think. But surely we shouldn't have an entitlement to a proposition like this - surely justification for this proposition should not come so cheaply.
} 
Epistemologists commonly distinguish between two kinds of anti-sceptical project in which one might engage. The aim of an ambitious response to the sceptic is to provide a defence of our commonsense position that even a sceptic ought to find compelling - to convince the sceptic, in this case, that our actual practices of inquiry are legitimate. In pursuing such a project, one is limited to premises that a sceptic is obliged to accept. The aim of a modest response to the sceptic, in contrast, is merely to protect our commonsense position against sceptical arguments that threaten to overturn it - to deflect arguments purporting to show that our actual practices of inquiry are illegitimate. In pursuing this kind of project, one is free to use premises that the sceptic may not accept - so long the sceptic has provided no reason to doubt them.

The notion of entitlement can be employed in the service of both kinds of antisceptical project but what I've undertaken here, at least as it stands, is best thought of as a project of the modest type. The sceptical argument that I described at the outset sought to discredit our practices of inquiry by extracting the presuppositions of these practices and calling them into question. I have argued that we are entitled to accept

In footnote 5, I distinguished two different ways to interpret my analysis of evidential support in terms of comparative world normalcy. On one approach, facts about world normalcy are taken to be determined by facts about evidential support - it is because E evidentially supports $\mathrm{P}$ that the most normal E-worlds are P-worlds. On this way of thinking, the maximally normal worlds should simply be regarded as those at which all evidential support relations 'pan out' - at which the presuppositions of all evidential support connections hold true. In this case, the scope of evidential inner necessity will include only the presuppositions of legitimate practices of inquiry (and the propositions that they entail).

Alternately, in interpreting my analysis of evidential support, we could put facts about comparative world normalcy in the driver's seat. On this approach, it is because the most normal Eworlds are P-worlds that E evidentially supports P. On this way of thinking, we will eventually have to supply some independent account of comparative world normalcy and it will fall to this account to spell out just what the maximally normal worlds are like and what propositions hold true at all of them. One criterion of adequacy for an account of world normalcy is presumably that it not lead to an epistemology that is overly permissive. Any candidate account of world normalcy should be answerable, ultimately, to our epistemic intuitions and not to raw judgments about world normalcy. 
the presuppositions of any legitimate practice of inquiry and that this claim can be underwritten by an analysis of the evidential support relation, motivated on independent grounds. While this may reassure us in the face of the sceptical argument, there is nothing here - or nothing obvious - that should force a sceptic to concede that our practices of inquiry are legitimate. Even if my analysis be accepted, the legitimacy of our practices of inquiry will turn upon certain suppositions about comparative world normalcy - and the sceptic is under no obvious compulsion to accept such suppositions ${ }^{19}$.

\section{SOME FEATURES OF ENTITLEMENT}

In this final section I shall briefly explore some significant features of the present conception of entitlement. One notable feature of entitlement, as presently conceived, is that it could, in principle, attach to propositions contingently. That is, whether we are entitled to believe a proposition could, on the present view, depend upon certain features of the world we inhabit. This, in any case, will be so if evidential conditionals can themselves hold contingently ${ }^{20}$. To put it slightly differently,

\footnotetext{
${ }^{19}$ As I've noted, my analysis of evidential support can be taken in (at least) two different spirits - one might think that facts about evidential support are primary and facts about comparative world normalcy are derivative, or one might think that facts about comparative world normalcy are primary and facts about evidential support are derivative. If the analysis be taken in the former way then a modest antisceptical response may be the most that we can hope for. If the analysis be taken in the latter way, however, then the path to an ambitious anti-sceptical response may lie open - provided that we can devise some independent way of settling questions about world normalcy to a sceptic's satisfaction.

${ }^{20}$ The idea that evidential conditionals are necessary corresponds roughly to what Lewis termed the local absoluteness constraint - for all worlds $\mathrm{w}_{1}, \mathrm{w}_{2}$, if $\mathrm{w}_{2}$ is a member of some sphere of normalcy assigned to $\mathrm{w}_{1}$ then $\mathrm{w}_{1}$ and $\mathrm{w}_{2}$ are assigned the same set of spheres of normalcy [see Lewis 1973: 99, 120-122]. If we let $\square$ be the outer necessity associated with the evidential conditional, then the two axioms that correspond to this constraint are:
}

(i) $\quad(\mathrm{P} \rightarrow \mathrm{Q}) \equiv \square(\mathrm{P} \rightarrow \mathrm{Q})$

(ii) $\quad(\mathrm{P} \diamond \rightarrow \mathrm{Q}) \equiv \square(\mathrm{P} \bullet \rightarrow \mathrm{Q})$

If it is permissible to read $\square$ as metaphysical necessity (see footnote 10) then we have the required result. 
entitlement will attach contingently - at least to certain propositions - if standards of normalcy are able to vary between different possible worlds.

The account, of course, doesn't dictate what kinds of worldly preconditions may be necessary in order for entitlement to a particular proposition to be in place indeed, it allows for maximal flexibility in this regard. Consider a possible world in which I am the only sentient being surrounded by automata. Would behaviour still constitute evidence, in a world like this, for the attribution of mental states? Many, I think, would want to say yes [see Cohen 1984] - but intuitions about these kinds of examples can differ. In any case, if the answer is 'yes', then I would still be entitled, in the world described, to believe in other minds - a verdict which suggests that my entitlement to believe this is absolute and has no preconditions upon it. If, on the other hand, the answer is 'no', then my entitlement to believe in other minds would lapse in the word described. The former verdict goes along with the idea that the sceptical world described imposes similar standards of normalcy to a non-sceptical world - and, as a result, estimates itself to be exceedingly abnormal. The latter verdict goes along with the idea that the sceptical world imposes very different standards of normalcy to a non-sceptical one - such that it would count as relatively normal by its own standards.

The final topic I shall consider here is whether entitlement, on the conception I have outlined, can be thought of as a genuinely epistemic status. A comparison with deontic conditionals may, once again, prove helpful here. Could one accept that deontic conditionals, as characterised by Lewis, have genuine moral import whilst harbouring doubts about whether the deontic inner necessity represents a genuine 
moral status? The answer, I think, is 'no'. If the consequent of a true deontic conditional is afforded a positive moral status once we learn the antecedent, then propositions that satisfy the deontic inner necessity must have a positive moral status inherently. This is a simple consequence of Lewis's framework and it is, surely, the right way to think about the content of the deontic inner necessity. To regard the consequent of a deontic conditional as desirable upon learning the antecedent only makes sense in so far as the deontic inner necessities are desirable unconditionally.

So it is, I suggest, with evidential conditionals. If the consequent of a true evidential conditional is afforded a positive epistemic status once we learn the antecedent, propositions that satisfy the evidential inner necessity must have a positive epistemic status inherently. To regard the consequent of an evidential conditional as believable upon learning the antecedent only makes sense in so far as the evidential inner necessities are believable unconditionally.

Worries about the genuinely epistemic status of entitlement are, I think, exacerbated by the fact that entitlement is often described as being non-evidential [Wright 1985: section III, 2004: 174-175] - a kind of justification that can attach to a proposition without evidence in its favour. It's natural enough that this might set off alarm bells - after all, one standard way of distinguishing epistemic justification from other kinds of justification is in terms of a dependence upon evidence [Conee and Feldman 1985, Williamson 2000: section 9.8, Fantl and McGrath 2002: 69, Conee: $2004]^{21}$. As I've discussed, though, this description of entitlement is not obligatory -

\footnotetext{
${ }^{21}$ Another, somewhat similar, thought is that what makes justification epistemic is truth-conduciveness of some kind - an epistemic justification for believing P, unlike a practical justification for believing $\mathrm{P}$, is conducive to the truth of $\mathrm{P}$. One who is impressed by this idea might challenge the epistemic status of entitlement by arguing that an entitlement to a proposition is disconnected from its truth. The
} 
and, in my view, concedes too much to the sceptic. On the present approach, entitlement should not be regarded as non-evidential at all.

The first thing to note is that a practice of inquiry could, in principle, license evidential transitions involving propositions that are simultaneously presuppositions of the practice. $E \boldsymbol{\square} \rightarrow \mathrm{S}$ and $\sim \mathrm{S} \diamond \rightarrow(\mathrm{E} \wedge \sim \mathrm{S})$ are perfectly consistent. Figure 1 depicts just such a situation (with $\sim \mathrm{D}$ substituted for $\mathrm{S}$ ). If I am engaged in a practice that incorporates this conditional, then it seems that I should not regard S as lacking evidential support. Citing $\mathrm{E}$ in favour of $\mathrm{S}$ is, in effect, what the practice recommends. Clearly, though, this would beg the question against a doubter - anyone who doubted $\mathrm{S}$ would be in no position to rationally avail himself of the evidential connection between $\mathrm{E}$ and $\mathrm{S}^{22}$. But this is not to say that there is no evidential connection between $\mathrm{E}$ and $\mathrm{S}$. The present model suggests that there could be such a connection, in spite of the fact that $\mathrm{E}$ could never constitute a doubt-conquering ground upon which to believe that $\mathrm{S}$.

As I mentioned in section II, when a proposition holds throughout all maximally normal worlds, any proposition that holds in some maximally normal worlds will, on my account, constitute evidence in its favour. Rather than thinking of entitlement as a kind of support that is non-evidential, it may be better to think of it as a kind of limiting case of the evidential support relation itself - a case in which the evidence relatum becomes, in a way, insignificant, since it can be relatively freely

present framework does, I think, have the resources to address this kind of concern - but I will only make this out roughly here. Suppose I earn a justification for believing that the wall is red by acquiring the evidence that the wall appears to be red. One reason that this justification might be deemed 'truth conducive' is that it forces possibilities in which the wall is not red further from ideal normalcy - it makes the falsity of the proposition less normal than it would otherwise be. On the present conception, though, an entitlement to a proposition is truth conducive in just this sense.

${ }^{22}$ Modulo the kinds of concerns expressed in footnote 17. 
substituted. If I'm entitled to believe a proposition, then I $d o$ possess evidence in its favour. It's just that the specific constitution of my corpus of evidence, whatever it happens to be, is of no particular consequence in making this so.

There is a certain pervasive picture according to which, if $\mathrm{E}$ constitutes evidence in favour of $S$ then $E$ should be potentially rationally persuasive for one who doubts S. The desire to preserve some such link between evidential support and rational persuasion is one kind of motivation for conceding that entitlement must be non-evidential. On the present way of thinking about evidence, though, the picture simply isn't feasible - not for every instance of the evidential support relation. Think about the corresponding requirement in the case of deontic conditionals: If there is a genuine deontic conditional connection between $\mathrm{P}$ and $\mathrm{Q}$ then $\mathrm{P}$ should be potentially rationally motivating for one who is initially disinclined to bring it about that $\mathrm{Q}$. This may hold true for many deontic conditionals, but will clearly fail for those limiting cases in which $\mathrm{Q}$ is a deontic inner necessity and $\mathrm{P}$ an unrelated deontic inner possibility. This, I take it, is not an objection to modelling deontic conditionals in the way suggested.

Many of the practices of inquiry in which we engage do indeed depend upon presuppositions that we have not investigated and cannot rationally defend. If a practice of inquiry is in good order - if the evidential conditionals that constitute it are true - then its presuppositions will, in virtue of this alone, count as evidential inner necessities and thus, on the present proposal, propositions that we are entitled to accept. 
This theory, in a way, vindicates another idea that one might find in the pages of On Certainty. In a particularly celebrated passage, Wittgenstein writes:

...the questions that we raise and our doubts depend upon the fact that some propositions are exempt from doubt, are as it were like hinges on which those turn.

That is to say, it belongs to the logic of our scientific investigations that some things are in deed not doubted.

But it isn't that the situation is like this: We just can't investigate everything, and for that reason we are forced to rest content with assumption. If I want the door to turn the hinges must stay put.

[Wittgenstein 1969: §341-343]

The way I read Wittgenstein here, what licenses us in believing certain things without investigating them is not the impracticality of letting our investigations snowball or the impossibility of investigating everything at once. Rather, the very idea of investigating a proposition - of gathering relevant evidence in order to make up my mind about something - already contains within it the idea that certain things will be believable without investigation. As such, there is a kind of incoherence, and not just an unfairness, to the sceptical demand that nothing be accepted without investigation.

University of Glasgow

\section{References}

Boutilier, C. 1994. Conditional logics of normality: a modal approach, Artificial Intelligence 68/1: 87-154 
Boutilier, C. and Becher, V. 1995. Abduction as belief revision, Artificial Intelligence 77/1: 43-94

Cohen, S. 1984. Justification and truth, Philosophical Studies 46/3: 279-295

Conee, E. and Feldman, R. 1985. Evidentialism, Philosophical Studies 48/1: 15-35

Conee, E. 2004. The truth connection, in Evidentialism: Essays in Epistemology ed. Conee, E. and Feldman, R., Oxford: Oxford University Press

Davies, M. 2003. Externalism, self-knowledge and transmission of warrant, in Meaning, Basic Knowledge and Mind: Essays on Tyler Burge ed. Frápolli, M. and Romero, E, CSLI Publications

Davies, M. 2004. Epistemic entitlement, warrant transmission and easy knowledge, Aristotelian Society Supplement 78/1: 213-245

Delgrande, J. 1987. A first order logic for prototypical properties, Artificial Intelligence 33/1:105-130

Dretske, F. 1970. Epistemic operators, Journal of Philosophy 67/24: 1007-1023

Dretske, F. 2000. Entitlement: Epistemic rights without epistemic duties?, Philosophy and Phenomenological Research 60/3: 591-606

Fantl, J. and McGrath, M. 2002. Evidence, pragmatics and justification, Philosophical Review 111/1: 67-94

Hansson, B. 1969. An analysis of some deontic logics, Noûs 3/4: 373-398

Hazlett, A. 2006. How to defeat belief in the external world, Pacific Philosophical Quarterly 87/2: 198-212

Huber, F. 2009. Belief and degrees of belief, in Degrees of Belief ed. Huber, F. and Schmidt-Petri, C., Dordrecht: Springer 
Jenkins, C. 2007. Entitlement and rationality, Synthese 157/1: 25-45

Korcz, K. 1997. Recent work on the basing relation, American Philosophical Quarterly 34/2:171-191

Kraus, S., Lehmann, D. and Magidor, M. 1990. Nonmonotonic reasoning: preferential models and cumulative logics, Artificial Intelligence 44/1-2: 167-207

Lewis, D. 1973. Counterfactuals, Oxford: Blackwell

Lewis, D. 1974. Semantic analyses for dyadic deontic logic, in Logical Theory and Semantical Analysis ed. Stenlund, S., Dordrecht: Reidel

Makinson, D. 1989. General theory of cumulative inference, in Non-Monotonic Reasoning ed. Reinfrank, M., Berlin: Springer-Verlag

Makinson, D. 1993. Five faces of minimality, Studia Logica 52/3: 339-379

McDowell, J. 1982. Criteria, defeasibility and knowledge, Proceedings of the British Academy 68: 455-479

McGinn, M. 1989. Sense and Certainty, Oxford: Blackwell

Pedersen, N. 2009. Entitlement, value and rationality, Synthese 171/3: 443-457

Pollock, J. 1974. Knowledge and Justification, Princeton, NJ: Princeton University Press

Pritchard, D. 2005. Wittgenstein's On Certainty and contemporary anti-scepticism, in Readings On Wittgenstein's On Certainty ed. Moyal-Sharrock, D. and Brenner, W., London: Palgrave Macmillan

Pryor, J. 2004. What is wrong with Moore's argument?, Philosophical Perspectives 18, Atascadero: Ridgeview Publishing 
Smith, M. 2009. Transmission failure explained, Philosophy and Phenomenological Research 79/1: 164-189

Smith, M. 2010 What else justification could be, Noûs 44/1: 10-31

Soames, S. 2002. Beyond Rigidity: The Unfinished Semantic Agenda of Naming and Necessity, Oxford: Oxford University Press

Tucker, C. 2009. Perceptual justification and warrant by default, Australasian Journal of Philosophy 87/3: 445-463

Van Fraassen, B. 1972. The logic of conditional obligation, Journal of Philosophical Logic 1/3-4: 417-438

Williamson, T. 2000 Knowledge and its Limits, Oxford: Oxford University Press

Wittgenstein, L. 1969 On Certainty, trans. by Paul, D. and Anscombe, G., Oxford: Basil Blackwell

Wright, C. 1985, Facts and certainty, Proceedings of the British Academy 71: 429-472

Wright, C. 2000, 'Cogency and question-begging: Some reflections on McKinsey's paradox and Putnam's proof' in Philosophical Issues 10, ed. Sosa, E. and Villanueva, E., Boston: Blackwell

Wright, C. 2002. (Anti-)sceptics, simple and subtle, Philosophy and Phenomenological Research 65/2: 330-348

Wright, C. 2003. Some reflections on the acquisition of warrant by inference, in New Essays on Semantic Externalism and Self Knowledge ed. Nuccetelli, S., Cambridge, MA: MIT Press

Wright, C. 2004. Warrant for nothing (and foundations for free)?, Aristotelian Society Supplement 78/1:167-212 